\title{
From Employable to Fully Operational: The Need for Training of Computer Science Graduates
}

\author{
https://doi.org/10.3991/ijep.v11i3.19995 \\ Gunhild M. Lundberg ( $\left.{ }^{\varpi}\right)$, Birgit Krogstie, John Krogstie \\ Norwegian University of Science and Technology, Trondheim, Norway \\ Gunhild.lundberg@ntnu.no
}

\begin{abstract}
For graduates in computer science and informatics to get employment as IT professionals, there is a need for their education to provide the competence sought after by employers. To become fully operational in the organization, the candidates typically also need to further develop their competence there, engaging in activities, and becoming familiar with the practices in the company. For a university offering master's degrees in computer science and informatics, it is important to know the employers' view of the relevance of the study programs and what is possibly considered to be lacking. Also, it is essential to know whether the missing part needed to become fully operational should be provided by the university. In this paper, we investigate these questions by asking employers of master students in IT. As a significant new contribution, we use the framework of modes of identification by Wenger-Trayner and Wenger-Trayner to find out if the graduates are aligned with the discipline, engaged in activities, and able to imagine their future in an IT-position. A combination of in-depth interviews and a survey is used. Analysis of the findings shows that employers overall find the candidates' competence from the university to be adequate. We argue that collaboration between university and industry is essential to this success, pointing to a set of key steps in the process from entering a study program to becoming fully operational in work life.
\end{abstract}

Keywords - Employability, Training, Higher Education, Computer Science, Graduates

\section{Introduction}

This article is based on an article published in EDUCON 2020 [1], which has been revised and extended. The significant new contribution includes a theoretical analysis based on the modes of identification framework by Wenger-Trayner and WengerTrayner [2]. Computer Science (CS) and Informatics is two different master programs at focus in this paper, where a master within CS contains more mathematics.

Being a new employee in an organization entails becoming a member of a community of practice [3], gradually developing expertise, and becoming more proficient in the organization's work practice. This is a learning process that can happen through formal and informal training. Workplace learning is always partially informal [4] and 
takes place as the employee is working and learning from experience and collaborating with colleagues. Additionally, formal in-house training can be provided. An employer recruiting new candidates from higher education (HE) expects to have candidates with an adequate starting point for this learning period, both the time to become "fully operational" and the continued and indeed life-long learning that follows.

Considering computer science and information technology graduates, the candidates usually get hired quickly after graduation. At the same time, companies spend substantial resources on training the candidates to become fully operational. For the HE institutions, it is of great importance to know whether the candidates have the right competence upon graduating and whether the following months and years in work-life make them the IT professionals needed by employers and society. Interesting questions to explore include: What does it mean to become fully operational? What are graduates trained in, and how long does it take to become fully operational within a company? Does the graduate lack any competence which should have been taught in HE?

Employability may be understood as the skills, knowledge, and personal attributes needed to get a job [5]. This is the possession perspective on employability [6]. In this article, however, we will look at employability from a process perspective, where identity formation is at focus [6]. In this perspective, employability could be seen as pre-professional identity formation, which "relates to an understanding of and connection with the skills, qualities, conduct, culture and ideology of a student's intended profession" [7]. Further, we see employability from the meso level, which is the industry and HE perspective [8]. Competence is in this article understood as the "ability to use knowledge, skills and personal, social and/ or methodological abilities, in work or study situations and in professional and personal development" [9]. When we talk about students/graduates "getting a job," we refer to relevant, normally full-time employment in commercial businesses or public sector, starting after completion of the university degree. Finally, for simplicity, we use the term "industry" to refer to employers in commercial businesses, public sector as well as NGOs.

Modes of identification, as defined by Wenger-Trayner and Wenger-Trayner [2] (previously modes of belonging [3]) is a way to describe how someone forms their identity through their participation in a landscape of communities. Modes of identification consist of three aspects: First, Imagination - where the ability to connect the past and the present will help students imagine their future, and could serve as a guideline for students' choices or exploration of new possibilities. Second, Engagement - where involvement in communities with different sets of competence gives students experience as they engage in practices, talk or debate, and use or produce artifacts. Third, Alignment - where students align to the discipline by coordinating their perspectives, actions and interpretations. In this article we will use modes of belonging as a perspective to find out how employers view students' identity formation in a hiring process.

In Norway, there is a relatively low unemployment rate in general $(3,9 \%$ was unemployed in 2018) [10]. Within the IT-field, we have a high and increasing demand for software programmers and application developers, as well as system architects and analysts, while other IT graduates seem to have some challenges getting a job, as 
reported in [11]. According to this report, there seems to be a mismatch between employer needs and the qualifications of the unemployed graduates. Accordingly, coordination between the employers and the HE sector is needed to make sure that the graduates get the qualifications sought after by employers [11]. A study of Norwegian bachelor students in a college in southern Norway found that $26 \%$ of the IT students get a relevant job without applying at all. Including students who sent between one and ten applications before they got a job, the employment rate is $78 \%$ of all IT bachelor graduates [12]. An internal report from the biggest university in Norway pointed that $95 \%$ of their master graduates had secured a job before delivering their master thesis. This shows that both bachelor and master level IT graduates in Norway are in demand in the labor market.

Online presence in social network sites is seen as important for career management and professional identity development by graduates [13]. In hiring situations, employers value the candidate's participation in online communities related to the candidate's field, e.g., GitHub or StackOverflow [14]. Visible achievements in such communities can give employers an impression of the graduate's coding skills. Hobby activities, such as having one's own programming projects, and staying updated in the field, are essential, providing an opportunity to demonstrate that the graduate can apply the knowledge gained in HE [15] and be aligned with the discipline. Also, engaging in extra-curricular activities like organizing events for student societies or other organizations might increase the chances of getting a job and contributes to learning new skills outside of the university [16]. This can broaden students' experience, which makes them able to imagine their future through other people's narratives and experiences [17].

Academic achievements are, of course, a key factor in the hiring process. In Norway, larger companies hiring IT professionals tend to focus on academic qualifications first, using grades as a selection criteria for interviews before looking into personal qualities [18]. Smaller IT companies, tend to start with personal attributes, to find out whether the person fits the company socially, before looking at the academic achievements [18].

Being aligned with the discipline is a key step to develop a pre-professional identity, where gaining skills, knowledge and having personal attributes relevant for the discipline is at focus. The candidates' communication skills (primarily written) are reported by employers as frequently too weak [19] or lacking[20]. Also, emotive communication should be emphasized in engineering education [21]. In addition to the communication skills, newly hired graduates also seem to lack collaboration skills, technical skills, cognitive skills, and orientation skills [22], or lack the ability to use these skills [23]. It is not the lack of "experience in programming, design or debugging" that causes problems for newly hired graduates, but the social conditions at the new workplace [22]. When a graduate is searching for employment, skills in areas like project experience and problem-solving often determine whether the graduate gets a job or not [24]. These non-technical skills are often underestimated by graduates [25].

Companies generally expect to take responsibility for teaching newly hired graduates' specific requirements for their job, because it is almost impossible to define what 
requirements the professional areas have towards graduates in any generic sense, even when focusing on only one requirement like writing [26]. Even within a company, there may be little agreement about what competence is most important [27].

Collaboration between the industry and the university makes them understand each other and could contribute to teaching graduates valuable skills through guest lectures and real-world insights to the students [28]. Some skills can also be hard to achieve through courses in a university setting (e.g., working with clients or work-life experiences) [24], and the educators should, therefore, consider telling the students what skills they do not learn at university so that they can find other areas to learn these skills [29].

A significant body of research argues that we need to educate students to become employable. From a process perspective on employability, this means helping the students become fully aligned with the discipline, engage in activities to gain competence, and imagine a future within the discipline. In the field of computer science in the Nordic countries, recent years have seen a shortage of people and a high demand for graduates with Computer Science degrees. This was the case in the autumn of 2019. More recently, the COVID situation has had an impact on the work market in Norway [30]. Given the current pandemic, it is interesting to investigate the effort needed in the organizations to make the graduates fully operational. To this end, in this paper we attempt to provide answers to a set of questions:

- Do employers hire graduates who lack knowledge needed in the company, and use resources to train them to get the needed competence, or are we educating students who already upon graduation fulfill the requirements from the industry?

- How do employers view students' employability from the perspective of modes of identification, where student's alignment, engagement, and imagination in the discipline and for an IT job are essential? How do employers influence student's preprofessional identity during their education period?

We differentiate between the discipline-, company-, and HE communities, where students become more competent in the discipline throughout their education and continue to develop their competence during their training and their employment. A student could be seen as not very competent in the HE community, but through engagement in hobbies and having own interest, he/she be counted as competent in the discipline. Also, each IT company forms their own community, and such communities have different ideas related to competency.

To investigate this, we have looked into employers' perspective on employability and the need for extra training for students from two specific study programs. In the next section, a description of the case is provided. We next present our research method before the results of the study are provided. An analysis is presented in the discussion section. The paper ends with a conclusion and an overview of related work. 


\section{Case}

For a more detailed case description, see [1]. The master study programs investigated in this study include one in computer science (MCS, 5 years integrated master) and one in Informatics (a 3+2-year program).

In the MCS program, the first two years consist of fundamental courses in computer science, mathematics, statistics and some courses in physics, philosophy, and science theory. In the third and fourth year, the students specialize in four main areas: Software, Databases and Search, Artificial Intelligence, and Algorithms and Computers.

This structuring into specializations reflects the traditional way of organizing the Computer Science field covering the Computer Engineering (CE), Computer Science (CS), Software Engineering (SE), and Information Systems (IS) areas of ACM Curricula [31], while also meeting the continuously developing needs of industry and society.

The Informatics master program offers students who already hold a Bachelor of Computer Science (except CE) similar possibilities to specialize in their fourth year, with some mandatory and some elective courses within each of four specializations.

For MCS and Master of Informatics students alike, the fifth year includes the Master thesis, which is often undertaken in collaboration with an external client from industry or public sector. While the MCS is more structured than the Informatics program, the programs in practice show significant overlap and are generally considered by employers as equal with regard to the candidates' level of competence. Both master programs have very high admission requirements, the MCS generally being regarded as the most attractive master program in computer science nationally. There are approximately 140 MCS students and 100 Master of Informatics students each year at this university.

Collaboration with industry happens in different ways, e.g., by having external stakeholders take client roles in student projects (e.g., in the context of research projects), be course examiners, take part in study program development, and visit as guest lecturers. These activities ensure that the study programs keep up to date with the industry's needs and simultaneously let industry benefit from the competence and recruitment potential inherent to these activities. To support close collaboration with relevant partners, the faculty has organized a formal network of key industry partners that can be involved in an advisory role when there is a need to gauge the needs and concerns of industry, e.g., when study programs are evaluated and changed. The industry network also arranges events offering industry contact, especially for students in their early years. The companies in the industry network hire regularly from the study programs at focus.

An important part of the picture when considering employment and employability of the candidates from the study programs addressed here is that the work market in fall 2019 was very favorable for the candidates. The students often get their first regular job early in their last year. In reality, the recruitment process starts earlier, as the industry (e.g., consultancy companies) frequently employ students for summer jobs after their fourth year, using the internship as an occasion to evaluate the candidates 
before possibly offering regular employment. A survey-based study showed that $87 \%$ of the master students had a relevant summer job by the time they finish their 4th year, and $64 \%$ of the master students report that they had such a job already in their 3rd year [32].

\section{Method}

In this chapter we will briefly describe the method used in this research. For a more detailed description, see [1].

The study presented in this paper used an exploratory research design [33] .The sampling approach included defining the sample universe and sample size, deciding on a sampling strategy, and recruiting the participants [34]. Our sample universe and inclusion criteria for the interviews were that the informant should: (1) have hired students from master's programs mentioned above, (2) be located in the same country as the master's programs, (3) work closely with students from the master's programs, (4) be a part of the industry network presented above. For the survey, the inclusion criteria were that the company should: (1) have hired students from master's programs mentioned above, (2) be answered by a leader for IT employees or someone else involved in hiring new IT employees.

The sampling strategy for the interviews and survey was convenience sampling. The survey combined this with purposive (quota) sampling to cover two strata (private and public sector).

A total of 16 e-mails were sent out to ask for an interview. We received 11 answers, and six respondents were willing to participate. Two of these respondents were from the same company but represented different roles and organization units, and they were both included in the sample as it was considered likely that they would provide different perspectives. The informants were managers or department leaders.

The interview questions targeted a) background and how familiar informants were with master's program, b) skills, knowledge and personal attributes a graduate have/should have/lack, and c) graduates' need for training and their expectations about work life.

The survey questions covered a) background and the informant's familiarity with the master's programs in question, b) education (competence gained through the study program) and training (competence gained after being employed in the organization), and c) employability (which positions newly hired graduates get, what are their strengths, other possible candidates for the position). The survey was tested out with several faculty members and iteratively improved. The answers were anonymous.

The survey was sent to all members of the above-mentioned industry network and additionally sent to a number of companies that have previously been hiring from the study programs. 50 invitations for the survey were sent out, resulting in ten respondents.

We have done a thematic inductive analysis, where we followed Braun and Clarke's six phases of thematic analysis [35]. First, we familiarized ourselves with the data before we identified and applied initial codes. Then we searched for themes and 
did a re-coding to make sure we got all relevant data coded. We defined the theme to be education and training, where graduates becoming fully operational was the main goal for employers. The analysis was data-driven, where the research questions were developed from the codes [35].

\section{$4 \quad$ Results}

We will here present the main results from the interviews and the survey and will clarify the source under each point.

Most students from the master programs in this case seem to get the same type of entry position when they start working, according to the data in the interviews and survey. Programmer, system developer, or software developer are the relevant positions mentioned. Other positions graduates are recruited for is researcher, data scientist, or android/web developer. There seems to be a common understanding that the employees remain in these positions only for a few years, before proceeding to another role. Informant 1 explains: "They have been recruited as a software engineer. Everyone starts in this position. [...] and then, after some years, it could be 3-6 years, things start to happen. You get promoted to an architect or team leader, project leader, or something like that".

\subsection{Skills, knowledge and personal attributes}

Several of the informants mentioned that they do not expect a graduate to have indepth knowledge, but a broader knowledge base, which the graduate can build on during their training. According to the informants, this knowledge base should contain two or more programming languages, math, algorithms and data structures, knowledge of security issues, and how to deal with them, UX, database, cloud development and knowledge on how to manage version control. Some informants also point out that graduates should know different paradigms for software development and understand different frameworks (Informant 1, 3, 4).

Other skills considered necessary by the informants are problem-solving skills, teamwork skills, communication skills (in different languages, and the ability to describe a technical problem to a nontechnical person), understanding of being part of a bigger system, and the ability to think holistically. Also, lifelong learning seems vital in the view of all informants, based on the argument that graduates should be able to acquire new knowledge fast as technology changes rapidly. Graduates should be able to quickly adapt and adjust to technological development.

A graduate's interest in the field is mentioned as a very important factor for hiring. Graduates should "convey their interest in the field, an interest in developing themselves in the field in which they have taken their education" (Informant 1). Further, it seems that the easiest way of deciding whether a graduate has this interest or not is by looking at the projects or hobbies in which they have been engaging. Otherwise, the graduate has to convince employers during the interview that they have the interest and the motivation needed. 
When asked about which skills and knowledge the graduates usually lack, most of the informant's answer "nothing specific." Two of the informants say they are happy with the knowledge and skills the graduates possess, but that the graduates use some time to learn agile development properly. In the survey, the lacking knowledge and skill areas mentioned the most were teamwork (cross-disciplinary and/or global teams), communication (with non-technical persons or persons from other fields) and agile development. There are no trends in the answers related to the size of the companies.

\subsection{Importance of grades}

How much emphasis a company puts on grades seems to differ; Some are more focused on getting graduates with experience and argue that "you could be a graduate with extremely bad grades which turns out to know a lot, but that the study situation is not entirely suitable for this person. Some of our best people have little or no education. [...] the reason [for this is] that we sought after graduates with extreme interests in programming and development, and we think that this [interest] is expressed through experiences" (Informant 5). Others are mentioning motivation and internal drive for the field as important factors when hiring graduates (Informant 1, 2). Some are more focused on the grades, arguing that a graduate should have a high-grade average, but that they allow some low grades - but that the graduate needs to be able to defend or explain why they have them (Informants 1,4 ).

Some of the informants argue that which courses a graduate has is important, and that they need high grades in the courses relevant for the company (Informants 4,6). One of the informants seems to disagree on the importance of personal attributes, arguing that it is an advantage to have a hobby outside of the education, but that they "do not hire people based on their personality" (Informant 6).

\subsection{Students' expectations}

Companies do not agree whether students have realistic expectations towards the employment. One company mentions that students do not know what types of work (work tasks) are associated with the typical roles in the work market. In a hiring situation, students get asked where they want to be after 3-5 years in the company and most of them answer system architect, however, few are able to explain what an architect does, according to informant 1.

Another informant wants students to be more visionary: "we need people to understand that the work they do could revolutionize the world. That is the motivation they should have when graduating. Believe that it is possible because it is!" (informant 2).

Some informants argue that students have realistic expectations towards employment, especially at the end of their education (informant 6), even though they might not have worked 8-hour days when they studied (informant 5). 


\subsection{What do the graduates learn in their company training?}

The companies report a variation of what graduates need training in to become operational in their company. Some inform that the graduates learn "a lot about the company, our strategy, visions. However, they also do some project work, which is closer to software development" (Informant 1). Others mention teamwork and use the time to define the new employees' role, responsibility, and contribution (Informants 2 , 4) and tools to use for version control, testing and quality assurance (Informant 4). Also, the quality of the product (Informant 2), and how to deal with large, complex systems with a large user group, and significant risks (Informant 4) are a part of the training in one of the companies in the study. One company runs a bootcamp in embedded programming to make sure that all new employees are on the same level (Informant 6).

In the survey, we see that smaller companies do not have a training program, but that the training happens while the new employees work, under close supervision by the nearest leader. The middle or bigger companies have an onboarding program taken by all new employees. Here graduates learn about the company - their rules, values, culture, and history. Some companies offer additional courses for the graduate to attend depending on which competence they lack and where they will start working. One company has answered that the graduates they hire usually do not need any additional competences to become fully operational, and that their training only includes "getting to know the company"-topics.

There are different opinions on how long it takes to make a student fully operational, ranging from six months to two years. Most of the informants think the time usage for training is as expected, while two of them think it is too long. One informant report that graduates mainly need to learn about the company during that time. In the survey we see that companies with fewer employees report a shorter training time for new employees. Also, some of the interviews address the time it takes to get fully operational: "... the new employees join a program that takes 3-4 years. Internal training, training, much traveling, you learn about the company, how we work." (Informant 1). Another informant argues that each employee needs a different amount of time to get fully operational.

To frame our results with respect to the modes of identification perspective, we consider the development of modes of identification as an ongoing process throughout education and training. In Figure 1, we provide a schematic view of the process a student/employee goes through. When starting at HE, students have some competence from high school, which is often reflected in their grades. The admission criteria at HE filter out the best candidates and offer them a study place. Students' competence increases during their education, and by the time students graduate, they are employable graduates and have developed a pre-professional identity. This stage lasts until the graduate gets hired, which is often right before graduation, or directly after, depending on which study program they graduate from. After being hired, the new employee takes part in some form of training program, formal or informal, which increases their competence enough for them to become fully operational employees. 


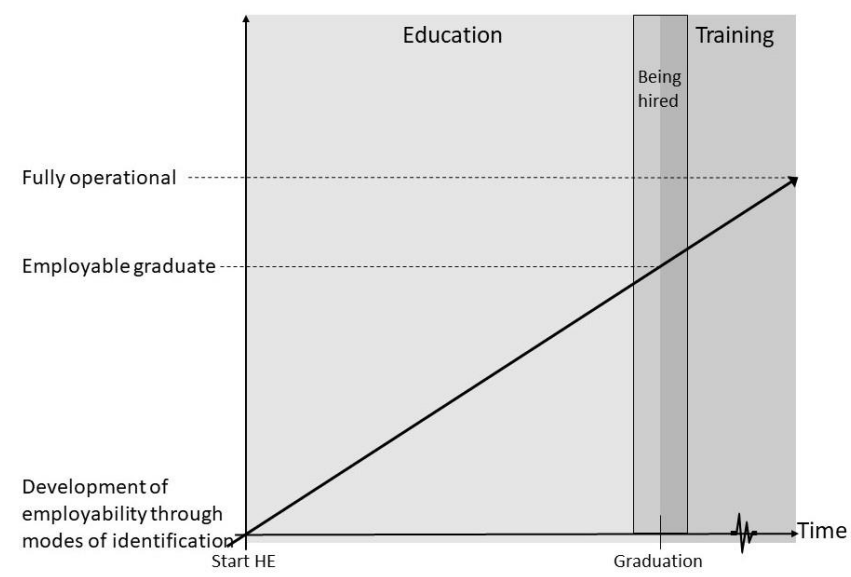

Fig. 1. Developing employability through modes of identification from the beginning of higher education until fully operational in a company

Although not shown in Figure 1, as described in the description of the case, recruitment can be seen as starting before graduation, especially through the summer jobs offered by the companies. Although this recruitment mainly applies to students between their 4th and 5th study year, students are also employed for summer jobs earlier on with recruitment in mind. Informant 1 explains: "We have had people from first-year computer science here. They have been here for 2 or 3 summers in a row. [...] I have tried to go in very early [to recruit students], between first and fourth year". The informant further states that summer jobs are perceived as a long interview for a position in their company.

\section{Discussion}

In our discussion of the results, we use the perspective of modes of identification to look at the employment setting as an acceptance of a student's pre-professional identity. Further, we look into which specific competence graduates need to become aligned with the discipline and obtain a pre-professional identity sought after by employers. Finally, we consider the process from education to becoming fully operational.

\subsection{Graduates' engagement, alignment and imagination}

The results indicate that many employers focus on the skills and knowledge students should have to become employed. Through modes of identification, we see that this could be understood as how experienced and how aligned the graduates are with the discipline. The informants mentioned frequently candidates' interest in the field as important, which is consistent with previous research (e.g., [15]). Projects related to 
volunteer and hobby activities demonstrate that the candidates have the skills as well as the drive and dedication sought after by many employers.

When students demonstrate that they have an interest in the field, they provide evidence for engaging in activities that give meaning for the community. By broadening their experience through participation in hobby activities, the students become able to imagine other opportunities, or perhaps more realistic opportunities, because they can explore their possibilities through other people's narratives. As described in the background section, students should look outside the university for acquiring skills not provided by the university [16].

As students get to know companies from early on in their education, they become able to imagine many of their job possibilities, and what they want to work with. By making sure that students are aware of their possibilities from early on, students can make informed decisions about which electives they should choose. Some students might also invest in hobbies or extra-curricular activities that make them able to pursue the job of their dreams. Some employers state that new employees must learn about what their responsibility are, what their role entails and what contribution they are expected to make, to ensure that they understand the cultural code in a company. That students are not able to imagine what people in different roles, e.g., an architect, do, but still think they will be able to fill those roles in 3-5 years, can indicate that they need more insight about their job possibilities.

One of the informants mentioned that they would like the graduates to become more visionary and imagine the possibility they have to make an impact in the world through developing revolutionary programs. However, students cannot imagine contributing to the world through revolutionary programs if they have no related experience, nor have gained any experiences through other people's narratives. To make students able to imagine these visionary contributions, someone need to tell them that it is possible, and give them narratives they can see themselves in. This is where industry collaboration through guest lectures and company presentations are important.

\subsection{Graduates' lack of alignment, engagement and imagination}

Previous research shows that the IT industry considers several skills important when hiring new employees. This includes problem-solving skills [24], communication [19], [22], and teamwork skills. Our findings are consistent with these studies. Answering about knowledge and skills found to lack among the graduates, several respondents mentioned agile development. This is a topic currently covered in the study programs, but there seems to be a gap between graduates' knowledge and what the industry expects from them. It seems that this has been an issue for several years, since several companies run bootcamps to secure that every new employee are familiar with the practices in the company. These bootcamps are also used for making sure that newly hired graduates have the same level of knowledge within e.g., the programming language used in the company. Bootcamps or training at the workplace could be seen as a way for employers to make students aligned with the company, knowing their practices in their community, and becoming engaged in activities that gives sense and meaning for the community. 
Along the same vein, several informants mentioned that additional knowledge and skills in teamwork and the ability to work in cross-disciplinary and/or global teams are needed to be fully operational in and aligned with their organization. Seeing these areas in connection, there is a potential for the university to address all of them through suitably designed student projects in agile development. Such projects can deliberately incorporate challenges and learning objectives related to crossdisciplinary [36] and/or global [37] teamwork, preferably with an external client to provide authenticity. On the other hand - all of this is already covered in existing project courses, which indicates that the university is already providing the right type of learning but might consider improving it and/or providing more of it. Students should be aware of the practices in the discipline, and students do learn them at university, however, it might seem as they do not learn them well enough.

Two informants from the survey report communication skills missing in the graduates. They specifically refer to communication with non-technical persons and crossdisciplinary communication, which could indicate that graduates' skills in communication with technical persons within the same field might already be at an appropriate level. Since only two companies report communication skills as lacking, it could imply that all other companies are pleased with the level of communication skills graduates have. Alternatively, as Moore and Morton argue, skills in written communication are often so company-specific that the companies expect to train the graduates in it when hired [26]. This shows that even though a student might be good in the skills seen as important by the discipline community, there is still a need for company communities to indoctrinate newly hired graduates to their form of competence.

It is a key finding in our study that most of the informants and participants answered "nothing specific" when asked about what skills are lacking in the graduates. This might indicate that the graduates that get hired generally do possess the skills needed in the IT discipline. It might also indicate that the companies are aware of some shortage of specific skills but accept this and include it in their training period. The findings should, in any case, be considered in light of the current high demand for computer science graduates: there is a chance that employers would respond differently had the work market been different.

Grades are, from the point of view of the HE institution, intended to reflect the candidate's level of skills as described in the learning outcomes of the courses and study programs. The disagreement between the employers on the importance of grades, may indicate that they are diverse in their thoughts on how modes of identification are achieved. Some employers might find evidence of engagement and alignment through grades or having "the right" electives, and others find this through interests, attitudes motivation or cultural understanding. It is known from the general recruitment practices of large consultancies that grades serve as a key mechanism for filtering out candidates for personal interviews [18]. The quote "We do not hire people based on their personality" (Informant 6). from one of our informants may be illustrative of this approach. The technical interviews and case assignments increasingly used by employers as part of their recruitment process serve to assess the candidates in essential ways with no connection to (although possibly a correlation with) grades. 
In seeing different views on desirable skills in new candidates and the significance of grades in employing them, we should also take into account that different skills are needed for different roles in different types of organizations, e.g., technical experts, scientists, and customer-oriented consultants. These differences mean there may be different reasons to consider grades in general and grades in specific types of courses in particular. Also, in the current work market, there is strong competition to get the best candidates, which means it can be harder for smaller companies with fewer resources for marketing and recruiting, e.g., startups, to compete for the best candidates. Having less visibility and perhaps less appeal to larger groups of students means there may be fewer candidates to select from, which makes getting the right person with the right motivation and practical/technical skills more important, e.g., as demonstrated through a technical interview.

\subsection{The process from education to becoming fully operational}

An employment processes can be understood as a learning process from a graduate point of view, where employers check if students are sufficiently aligned, engaged and able to imagine so that they can work in the company. One can say that the employers define if you have shown a pre-professional identity that is of their interest, or if the student are not professional enough in their point of view.

As explained in the Case section, there is a significant collaboration between the university and industry to ensure the relevance of the study programs in question. We believe the close collaboration between industry and university, including the student associations, to be essential in explaining the overall satisfaction with students' skills seen among the employers in our study; students are aligned, engaged and have the possibility to imagine their future.

Based on 1) the number of employed students, 2) that the industry think that the time used for training is as expected, and 3) that several of the companies think the graduates have the expected competencies needed to get a job, one could call the process from education to fully operational graduates a success, as graduates are being aligned with the discipline, engaged in activities that give meaning to the community, and able to imagine themselves in a future job. We see five interconnected and related key steps in the process of becoming fully operational: 1) Admission to the HE programs, 2) Introduction to the industry through HE, 3) Summer jobs, 4) The recruiting process, and 5) Training in the industry. In what follows, we will elaborate on these steps.

Admission requirements for the HE program: Due to the popularity of the study program, the admission requirements are high, making it hard to enter. This is affecting which students enroll in the study program, and how dedicated and engaged they are in their learning. Highly competent students, when they arrive at a study program, give highly competent students graduating from the study program [38]. The admission requirements thus affect the competence of the graduates, making them more competent compared to study programs with lower admission requirements.

Introduction to the industry through HE (guest lecturers, events): Close collaboration with the industry leads to guest lectures and events for students held by the 
industry like career days, presentations of the industry with additional dinner and drinks, courses held by the industry for the students, and speed interviews for summer jobs. The collaboration makes students able to imagine which jobs they are able to get, and what it entails to work in these jobs. Students get to know the companies before they apply for a job at them and get a closer understanding of which company that matches the students' interests and values, and how students can work to become more aligned towards their dream job.

Summer jobs: Several of the companies have opportunities for the students to get a summer job, which makes the student get to know the companies well, and the companies have an opportunity to get to know the students well. The summer jobs give the students experience in their field, as well as they will develop an understanding of how work life will be. Students are able to get to know cultural codes, and practices which make them aligned toward the company and the discipline. Through extending their experience, students become more able to imagine their future, and connect their past and present, making choices in the present that will help them in the future. A summer job could also provide students with additional skills not provided by HE [39]. On the other hand, students who did not get a summer job might be negatively affected: both in terms of not having the experience to put on their $\mathrm{CV}$, but also their self-esteem might be affected.

The recruiting processes: The recruitment process starts already from the first time the industry meets the students. Through courses and guest lectures held for the students, companies might seek out talented students and make them motivated to apply for a job after graduation early on. Several informants state that they see summer jobs as a long interview for a position in their company. This could make the student hopeful that he/she will get a job, and perhaps mentally "lock" themselves to one firm already from the first year. Recruiting students early or hiring students before graduation might affect their motivation in positive (I have got a job, I would not disappoint them) or negative (I got a job, I can relax and not worry about the grades) direction. This needs further research. If the student has not been recruited through summer jobs, several of the companies report that they have interview rounds with case and technical tests.

Training in the industry: After getting a job, students get a period of training within the company. Some have intensive courses everyone must attend, while others have a more learning-through doing method as described further above. This will make students become aligned with the company - knowing their practices, culture and norms.

The process as described here reflects the situation before the COVID-19 pandemic, and the current situation have affected the number of unemployed students with a master degree [30]. There is reason to believe that events arranged by the industry for students and the possibility to get summer jobs have became fewer in 2020, but the effect of this will first be apparent in 2021 and later. This could affect students' ability to align with companies and gain experiences that makes them able to imagine their future. Also, engaging in hobby activities together with others, and participate in training after being hired have become harder. Unless the training and the hobbies take place online, students and newly hired graduates might have problems attending 
it. This could, in the long term, make students less aligned with the discipline, unable to engage in activities seen as important by the discipline and company community. Without hearing narratives from companies and becoming able to use the experiences of others to imagine their future, students will be less prepared for employment. We as a university should make sure that we avoid this, and continue to hold close collaboration with the industry, to make sure that students get to know them and their work.

\section{Conclusion and Future Work}

The study presented in this paper shows that even though there is a high demand for IT graduates, companies do not hire candidates who lack the right competencies. Employers report that they are pleased with the competencies graduates possess when hired, which could be a result of a recruitment process that is complex, long-term, and based on close collaboration between the university and industry. We have shown that the recruitment process is complex, starting from the students' first year at the university, and that it involves a process of engagement, alignment and imagination on part of the students This use of modes of identification framework represents a novel contribution to employability research.

We see that even though students might be aligned with the discipline community and that they get good grades in their courses, they still need to take onboarding programs and have a training period. We see this as a process as becoming aligned with the company community. As several informants have mentioned, newly hired graduates need to get to know the company culture, practices, and norms. This alignment to the company cannot happen in the HE institution because they cannot prepare students for all the different companies. The focus on grades and hobby activities could indicate how well the graduate are engaged and aligned with the discipline, which could help employers to understand how much more training is needed to become aligned with the company as well. If a graduate is not well aligned with the discipline, it would be harder for the company to make the graduate aligned for the company, since many of the discipline specific practices also are used by companies in their everyday life.

Collaboration with the university gives the industry a better understanding of what training they need to provide to close the gap between the competence to be expected from a candidate at graduation and the one needed for being fully operational in work life. The collaboration between employers in the IT industry and the institutions educating IT candidates thus results in a clarification of expectations regarding employability.

A limitation to the study is the relatively small sample. The sample is large enough to show the variety in the recruitment process of CS and Informatics master graduates in Norway, however, having a larger sample might have shown which training processes companies tendence to use or a bigger variety in the training processes. Future work, including a larger sample and possibly an international sample, could show the differences in training between larger and smaller companies, pure IT companies and 
companies in other domains who are extensive users of IT, or Norwegian and international companies.

\section{$7 \quad$ Acknowledgement}

Thanks to K. A. Strand, B. Deraas, and H. Løkensgard for their contributions to the empirical study.

\section{$8 \quad$ References}

[1] G. M. Lundberg, B. R. Krogstie, and J. Krogstie, "Becoming Fully Operational: Employability and the Need for Training of Computer Science Graduates," EDUCON, pp. 644651, 2020, https://doi.org/10.1109/educon45650.2020.9125188

[2] E. Wenger-Trayner and B. Wenger-Trayner, "Learning in landscape of practice: A framework," in Learning in Landscapes of Practice: Boundaries, Identity and Knowledgeability in Practice-Based Learning, Routledge, 2015, pp. 13-29.https://doi.org/10.4324/ 9781315777122-3

[3] E. Wenger, Communities of Practice: Learning, meaning and identity. Cambridge University Press, 1999.

[4] M. Eraut, "Informal learning in the workplace," Studies in Continuing Education, vol. 26, no. 2, pp. 247-273, Jul. 2004, https://doi.org/10.1080/158037042000225245

[5] M. Yorke, Employability in higher education: what it is - what it is not, vol. 1. York: Higher Education Academy, 2006.

[6] L. Holmes, "Competing perspectives on graduate employability: possession, position or process?" Studies in Higher Education, vol. 38, no. 4, pp. 538-554, May 2013, https://doi.org/10.1080/03075079.2011.587140

[7] D. Jackson, "Re-conceptualising graduate employability: the importance of preprofessional identity," Higher Education Research \& Development, vol. 35, no. 5, pp. 925-939, Sep. 2016, https://doi.org/10.1080/07294360.2016.1139551

[8] J. G. L. Thijssen, B. I. J. M. Van der Heijden, and T. S. Rocco, "Toward the Employability-Link Model: Current Employment Transition to Future Employment Perspectives," Human Resource Development Review, vol. 7, no. 2, pp. 165-183, Jun. 2008, https://doi.org/10.1177/1534484308314955

[9] European Commission, The european qualifications framework for lifelong learning (EFQ). Luxembourg: Office for Official Publications of the European Communities, 2008.

[10] European Commission, "Eurostat - your key to european statistics," Employment and unemployment. https://ec.europa.eu/eurostat/web/lfs/visualisations (accessed Aug. 02, 2019).

[11] Official Norwegian Report, "Fremtidige kompetansebehov II - utfordringer for kompetansepolitikken," Oslo, 2019.

[12] E. Bostrøm, H. R. Garder, M. Næss, Ø. Syversen, and P. C. Veien, "Hva arbeider tidligere IT-studenter ved høgskolen i Østfold med, og hvor relevant har utdanningen deres vært for nåværende jobbsituasjon?” NOKOBIT, vol. 26, p. 14, 2018.

[13] A. Istenic Starcic, M. Barrow, M. Zajc, and M. Lebenicnik, "Students' Attitudes on Social Network Sites and their Actual Use for Career Management Competences and Professional Identity Development," iJET, vol. 12, no. 05, p. 65, May 2017, https://doi.org/10.3991/ ijet.v12i05.6778

[14] K. Raaen and P. Lauvås, "How companies find and evaluate graduate computer programmers," NIK, p. 12, 2018. 
[15] G. M. Lundberg, A. Gaustad, and B. R. Krogstie, "The employer perspective on employability," EDUCON, pp. 909-917, 2018, https://doi.org/10.1109/educon. 2018.8363327

[16] S. James, C. Warhurst, G. Tholen, and J. Commander, "What we know and what we need to know about graduate skills," Work, Employment and Society, vol. 27, no. 6, pp. 952963, Dec. 2013, https://doi.org/10.1177/0950017013500116

[17] L. S. Vygotsky, "Imagination and Creativity in Childhood," Journal of Russian and East European Psychology, vol. 42, no. 1, pp. 7-07, 20041930.

[18] P. Lauvås and K. Raaen, "Passion, cooperation and JavaScript: This is what the industry is looking for in a recently graduated computer programmer," NIK, 2017.

[19] T. L. Clokie and E. Fourie, "Graduate Employability and Communication Competence: Are Undergraduates Taught Relevant Skills?" Business and Professional Communication Quarterly, vol. 79, no. 4, pp. 442-463, Dec. 2016,https://doi.org/10.1177/2329490616 $\underline{657635}$

[20] I. Holik and I. D. Sanda, "The Possibilities of Improving Communication Skills in the Training of Engineering Students," iJEP, vol. 10, no. 5, p. 20, Oct. 2020, https://doi.org/10. 3991/ijep.v10i5.13727

[21] P. H. Lappalainen, "Can and Should Social Competence be Taught to Engineers?" iJEP, vol. 1, no. 3, p. 13, Oct. 2011, https://doi.org/10.3991/ijep.v1i3.1811

[22] A. Begel and B. Simon, "Novice software developers, all over again," 2008, pp. 3-14, doi: $10.1145 / 1404520.1404522$.

[23] A. Y. Aleryani and A. A. AlMunifi, "A Roadmap to the Development of Key Competencies of Engineering and Technology Graduates," iJEP, vol. 9, no. 5, p. 75, Nov. 2019, https://doi.org/10.3991/ijep.v9i5.11094

[24] A. Radermacher, G. Walia, and D. Knudson, "Investigating the skill gap between graduating students and industry expectations," 2014, pp. 291-300, https://doi.org/10.1145/2591 062.2591159

[25] V. Parts, M. Teichmann, and T. Rüütmann, "Would Engineers Need Non-technical Skills or Non-technical Competences or Both?" iJEP, vol. 3, no. 2, p. 14, Mar. 2013, https://doi.org/10.3991/ijep.v3i2.2405

[26] T. Moore and J. Morton, "The myth of job readiness? Written communication, employability, and the 'skills gap' in higher education," Studies in Higher Education, vol. 42, no. 3, pp. 591-609, Mar. 2017, https://doi.org/10.1080/03075079.2015. 1067602

[27] M. Hewner and M. Guzdial, "What game developers look for in a new graduate: interviews and surveys at one game company," SIGCSE, pp. 275-279, 2010.https://doi.org/10. $\underline{1145 / 1734263.1734359}$

[28] T. T. Tran, "Enhancing graduate employability and the need for university-enterprise collaboration," Journal of Teaching and Learning for Graduate Employability, vol. 7, no. 1, p. 58, Nov. 2016,https://doi.org/10.21153/jtlge2016vol7no1art598

[29] P. L. Li, A. Ko, and J. Zhu, "What Makes a Great Software Engineer?" May 2015, pp. 700-710, doi: 10.1109/ICSE.2015.335.

[30] L. A. Støren et al., "Arbeidsmarkedet for IKT-kandidater med høyere utdanning," NIFU, Oslo, 15, 2020.

[31] ACM, "Curricula Recommendations." https://www.acm.org/education/curricularecommendations (accessed Aug. 05, 2019).

[32] S. Wold and B. R. Krogstie, "Getting a Relevant Summer Job in IT," 2019, pp. 45-49, [Online]. Available: https://www.ntnu.no/ojs/index.php/njse/article/view/2992/2918.

[33] M. Borrego, E. P. Douglas, and C. T. Amelink, "Quantitative, Qualitative, and Mixed Research Methods in Engineering Education," Journal of Engineering Education, vol. 98, no. 1, pp. 53-66, Jan. 2009, https://doi.org/10.1002/j.2168-9830.2009.tb01005.x

[34] O. C. Robinson, "Sampling in Interview-Based Qualitative Research: A Theoretical and Practical Guide," Qualitative Research in Psychology, vol. 11, no. 1, pp. 25-41, Jan. 2014, https://doi.org/10.1080/14780887.2013.801543 
[35] V. Braun and V. Clarke, "Using thematic analysis in psychology," Qualitative Research in Psychology, vol. 3, no. 2, pp. 77-101, Jan. 2006, https://doi.org/10.1191/1478088706 qp063oa

[36] D. Foster, F. Gilardi, P. Martin, W. Song, D. Towey, and A. White, "Students as coproducers in a multidisciplinary software engineering project: addressing cultural distance and cross-cohort handover," Teachers and Teaching, vol. 24, no. 7, pp. 840-853, Oct. 2018, https://doi.org/10.1080/13540602.2018.1486295

[37] J. M. Bass, R. McDermott, and J. T. Lalchandani, "Virtual Teams and Employability in Global Software Engineering Education," in 2015 IEEE 10th International Conference on Global Software Engineering, Ciudad Real, Spain, Jul. 2015, pp. 115-124, https://doi.org/10.1109/icgse.2015.21

[38] Universitets- og høgskolerådet, "Karakterbruk i UH-sektoren," Universitets- og høgskolerådet, 2015.

[39] D. J. Deming, "The Growing Importance of Social Skills in the Labor Market*," The Quarterly Journal of Economics, vol. 132, no. 4, pp. 1593-1640, Nov. 2017, https://doi.org/10.1093/qje/qjx022

\section{Authors}

Gunhild M. Lundberg is a PhD candidate within Information Technology at the Computer Science Department at the Norwegian University of Science and Technology (NTNU). She holds a MSc (2016) in Digital Collaboration from NTNU. Lundberg is a part of Excited Centre of Excellent IT Education. She researches employability, identity formation and the feeling of belonging within Computer Science. Email: Gunhild.lundberg@ntnu.no

Birgit R. Krogstie holds a PhD (2010) and a MSc (1994) in Computer Science from the Norwegian University of Science and Technology (NTNU). She also has a Master's degree in Education (2000) from the University of Oslo. Krogstie is an associate professor at NTNU Department of Computer Science and vice lead of Excited Centre of Excellent IT Education. Her research interests include computing education, reflective learning, and computer-supported cooperative work.

John Krogstie holds a PhD (1995) and a MSc (1991) in information systems from the Norwegian University of Science and Technology (NTNU), where he is currently a full professor in information systems at the computer science department (IDI). At IDI he is currently the Department Head. His research interests are information systems engineering, quality of models and modelling languages, eGovernment and sustainable smart cities. He has published more than 350 refereed papers in journals, books and archival proceedings since 1991.

This article is a revised version of a paper presented at the EDUCON2020 conference held virtually in Porto, Portugal, 27-30 April 2020. Article submitted 2020-11-23. Resubmitted 2021-03-24. Final acceptance 2021-03-28. Final version published as submitted by the authors. 